\title{
Aflatoxin and its Public Health Significance: A Review
}

\author{
Mohammed Fedlu*, Ahmed Seid, Assaye Wollelie and Amana Mama \\ School of Veterinary Medicine, Wolaita Sodo University, Ethiopia
}

Submission: April 30, 2019; Published: June 11, 2019

*Corresponding author: Mohammed Fedlu, School of Veterinary Medicine, Wolaita Sodo University, Wolaita sodo, Ethiopia

Abstract

Aflatoxins are a group of mycotoxins produced by certain fungi, especially Aspergillus flavus and Aspergillus parasiticus. Aflatoxicosis is a condition caused by aflatoxin in both animals and humans. The contamination of food and feed with aflatoxin has serious health consequence in animal and humans as well as economic impacts especially in developing countries. Aflatoxin M1 is stable in raw milk and processed milk products and is unaffected by pasteurization or processing into cheese and yogurt. The ability of this toxin to induce cancer in experimental animals and the relatively large consumption of milk by children has made in food contaminant of worldwide concern. Aflatoxin exposure is mainly problem in poor and developing countries with poor regulation authority in food processing, storage and weather condition as well as with high level malnutrition all species of animal are susceptible to aflatoxicosis. Although we can control and eradicate the incidence of aflatoxin by using different strategy. A primary strategy should aim to eliminate aflatoxins by reducing mould proliferation during Cultivation and storage and also different methods are used to decontaminate food and feed before ingestion. Different methods for detection and quantification of aflatoxins have been employed in this document for agricultural food crops and feeds have been explored. While chromatographic methods such as TLC, HPLC and ELISA are thus the most widely used techniques in aflatoxins analysis.

Keywords: Aflatoxicosis; Economic; Milk Product; Public Health; Tumor

Abbreviations: Ab: Antibody; AFB1: Aflatoxin B1; AFBO: Aflatoxins B1-8, 9-epoxide; AFS: Aflatoxins; CYP450: cytochrome P450 enzyme; DO: Deoxynivalene; ELISA: Enzyme Linked Immune Sorverbent Assay; GH: Gas Gromatography; GIT: Gastrointestinal tract; HPLC: High performance Liquid chromatography; TLC: Thin layer chromatography; ZEA: Zearalenone

\section{Introduction}

Aflatoxins are a group of mycotoxins produced by certain fungi, especially Aspergillus flavus (A. flavus) and Aspergillus parasiticus (A. parasiticus) [1]. A. flavus and A. parasiticus are economically important molds that produce exclusively aflatoxin B1, B2, G1 and G2, and all the other aflatoxins are derivatives of these four aflatoxins [2]. According to Ruiqian [3], A. flavus and the closely related species, A. parasiticus have a worldwide distribution and normally occur as saprophytes in soil and many kinds of decaying organic matter. It colonizes a wide variety of food commodities including maize, oil seeds, spices, groundnuts, tree nuts, milk, and dried fruit [4]. Aflatoxigenic fungi produce four major aflatoxins: B1, B2, G1 and, G2 plus two additional metabolic products, M1 and M2, that are of significance as direct contaminants of foods and feeds [5].

Aflatoxin B1 (AFB1) has a great concern because of its detrimental effects on the health of animals and, humans including carcinogenic, mutagenic, teratogenic, and immune suppressive effects [6]. Upon ingestion by ruminants, AFB1 is partially destroyed in the rumen whereas the absorbed AFB1 rapidly undergoes metabolic processes in the liver to various secondary metabolites [7]. Consequently, over 5 billion people in developing countries worldwide are at risk of chronic exposure to aflatoxins through contaminated foods (Williams et al., 2004). Risk of human exposure to AFM1 contamination of milk is a major concern in Ethiopia where dairy farmers commonly use different mixed concentrate feeds containing traditional brewery by-product ("atela"), wheat bran, noug (Guizotia abyssinica) cake, maize grains, and silage to increase production. However, these feeds are susceptible to contamination with AFB1 [8].

Milk shed is selected for studies because it is a rapidly intensifying system where aflatoxins are likely to be an increasing problem. Fresh milk which is often consumed in developing countries without treatment poses a high risk to consumers [9]. Aflatoxin poisoning has been associated with eating home grown maize and storing it under damp conditions [10]. The application of these strategies in developing countries is difficult, given differences in technology, agriculture, and trade practices, as well as other issues contributing to occurrence of aflatoxins and incidence of exposure. Studies have indicated aflatoxin contamination in Ethiopia in staple cereals [11]. Aflatoxins must be removed from food and feed sources through various methods such as detoxification on larger scale so that to prevent great 
economic loss and illnesses in human beings and animals [12]. Agricultural interventions are methods or technologies that can be applied either in the field ("pre-harvest") or in drying, storage, and transportation ("post-harvest") to reduce aflatoxin levels in food [13]. Aflatoxins are regulated in more than 80 countries; their legislation is not yet completely harmonized at the international level [14].

Therefore, the objectives of this review paper are:

- To highlight on the aflatoxin.

- To review on public health and economic significance of Aflatoxin.

\section{Aflatoxicosis and its Predisposing Factors}

Aflatoxins are secondary metabolites produced by the common molds of A. flavus, A. parasiticus and A. nominus. These fungi are ubiquitous in the environment and produce aflatoxin in warm (30$35^{\circ} \mathrm{C}$ ) and high-humidity conditions. The occurrence of aflatoxins in agricultural commodities depends on region, season and the conditions under which a particular crop is grown, harvested or stored. Crops grown under warm and moist weather in tropical or subtropical countries are more prone to aflatoxin contamination than those in temperate zones. Aflatoxin production is also stimulated by high zinc concentration in feed [15].

Aflatoxin contamination occurs at every stage of the supply chain, from preproduction to post-harvesting, marketing and distribution. Aflatoxin accumulation during post-harvesting is a particular challenge for Africa. Food and feed contamination with AFS like soyabeans, maize, oilseeds, spices, peanuts, tree nuts (almonds, pistachios, hazelnuts, pecans, Brazil nuts, and walnuts), milk (in the form of aflatoxin B1"s metabolite aflatoxin M1), milk product and dried fruit [16]. These are found in many foods and considered as major public health problem especially in developing countries where long term food storage is often inadequate for high heat and humidity, which encourage the growth of mold. Their production can be influenced by several factors, including temperature, water activity, $\mathrm{pH}$, available nutrients, and competitive growth of other microorganisms [17].

The most important factors that help predict the occurrence of aflatoxins in food include weather conditions, agronomical practices (crop rotation and soil cultivation) and internal factors of the food chain (drying and storage conditions). A comprehensive approach is needed to identify and control risks related to good production system that could present a potential hazard to human health, being necessary to identify emerging risks which may include "newly" identified risks, not previously observed risks in human or animal food chain as well as known risks. The emerging risks need to be identified as early as possible in order to take appropriate preventive measures. Thus, the specific risk can be prevented from becoming a danger [18]. Subsistence farmers in developing countries are perhaps the most at risk. They often lack the capacity to protect crops against aflatoxin contamination. In addition, food insecurity due to drought and other causes of crop failure seem to contribute to behaviors that increase risk of exposure. Finally, $60-85 \%$ of the population in the developing world is subsistence farmers and is not protected by commercial food safety regulation [19] (Figure 1).

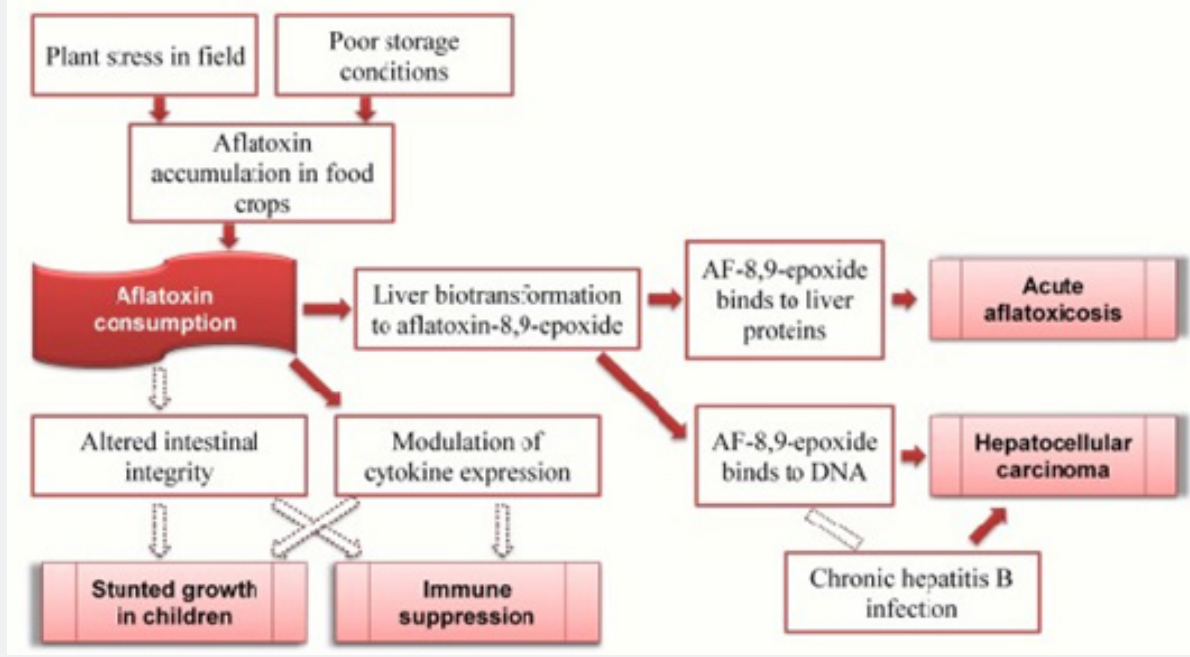

Figure 1: Aflatoxin disease pathways in humans $[13,50]$.

\section{Toxicity and Detoxification of Aflatoxin}

Toxicity of Aflatoxin: Aflatoxins are highly lipid soluble compounds and are readily absorbed from the site of exposure usually through the gastrointestinal tract (GIT) and respiratory tract into blood stream [20]. Aflatoxin B1 itself is not a potent toxin, and phase I bioactivation is needed to exert toxic effects.
Phase I reactions are mainly oxidation of AFB1 to hydroxylated metabolites such as aflatoxin M1 [21]. Bioactivation is required for AFB1to be toxic and this processing predominantly occurs in hepatocytes [22]. Aflatoxins have been recently considered as an important sanitary problem because it has been demonstrated that human exposure to mycotoxins may result from consumption 
of plant derived foods that are contaminated with toxins and their metabolites (which are present in animal products such as milk, meat, visceral organs and eggs) or exposure to air and dust containing toxins [23].

Aflatoxin can cause both acute and chronic aflatoxicosis. Aflatoxins, once ingested (because of their low molecular weight), are rapidly adsorbed in the gastro-intestinal tract through passive mechanism, and then quickly appear as metabolites in blood after just 15 minutes and in milk as soon as 12 hours post-feeding [24]. Early toxicological studies focused on the acute toxic effects of aflatoxins on animals, and demonstrated that ducklings, hamsters, rabbits, trout, rats, and a number of other vertebrates were all susceptible. Soon it was discovered that aflatoxins administered in lower doses over longer periods of time could induce tumors, particularly in the liver. Rats and trout were highly susceptible to the carcinogenic effect of aflatoxin B1 [25].

Aflatoxicosis is defined as the poisoning that results from ingesting aflatoxins. There are two forms that have been identified, the first is acute severe intoxication, which results in direct liver damage and subsequent illness or death, and the second is chronic sub symptomatic exposure. The effects are usually subclinical and difficult to recognize. Some of the common symptoms are impaired food conversion and slower rates of growth with or without the production of overt aflatoxin syndrome [26]. The effects of aflatoxins on humans, as with animals, are dependent upon dosage and duration of exposure [27]. The toxicity and carcinogenicity of AFB1 is thought to be directly linked to its bioactivation, resulting in a highly reactive AFB1 8, 9-epoxide (AFBO). This bioactivation of AFB1 occurs primarily by a microsomal cytochrome P450 (CYP450) dependent epoxidation of the terminal furan ring of AFB1 and is responsible for binding to cellular macromolecules such as DNA, RNA and other protein constituents [28]. The formation of AFB -DNA adduct is highly correlated to the carcinogenic effect of AFB in both animal and human cancer cases [29]. The International Cancer Research Institute identifies aflatoxin B1 as a Class 1 carcinogen, resulting in the regulation of this mycotoxin at very low concentrations in traded commodities (20 ppb in grain and $0.5 \mathrm{ppb}$ in milk in the United States; 4 ppb in foods in some European countries) [30].

Detoxification of Aflatoxin: The increasing number of reports on the presence of aflatoxins in food and feedstuffs dictates the need for decontamination procedures; such procedures should not only reduce the mycotoxin content to "safe" levels below regulatory limits but should also have the following characteristics: easy to use, inexpensive and free of the potential for forming compounds that are still toxic or compromising the nutrinal value of the treated commodity [31]. Although numerous detoxification methods have been tested, only some of them seem to be able to fulfill the efficacy, safety, safeguarding measures of nutritional elements and costs requisites of a detoxification process. These methods can be divided into three subcategories, which are physical, chemical and biological techniques [32].
Physically, aflatoxin contaminated seeds can be removed by hand picking or photoelectric detecting machines, but this is labor intense and expensive. Heating and cooking under pressure can destroy nearly $70 \%$ aflatoxin. Dry roasting can reduce about 50 $70 \%$ of aflatoxin and sunlight drying of aflatoxin contaminated feed could reduce the toxin level by more than $70 \%$ [33].

Biologically, which are based on the action of microorganisms on mycotoxins and their mechanism of action is based on competition by nutrients and space, interactions, and antibiosis, among others [34]. Biological control of mycotoxin is a promising approach for reducing both pre harvest and postharvest mycotoxin contamination in food crops [35]. Different organisms, including bacteria specially, probiotics and dairy strains of lactic acid bacteria, yeasts strains of Saccharomyces cerevisiae and nontoxigenic Aspergillus fungi, have been tested for their ability in the control of AFs contamination [36]. Chemically, there is no reliable method for feed decontamination from aflatoxin, various workers have screened a large number of chemicals viz. benzoic acid, propionic acid, copper sulphate, synthetic zeolites, citric acid etc. these chemicals have shown the reduction of aflatoxin in vitro [37].

\section{Detection Methods of Aflatoxin}

Various analytical methods employed in analysis of aflatoxins in agricultural food crops and feeds have been explored. While chromatographic methods such as TLC, HPLC and ELISA are considered the gold standard and are thus the most widely used techniques in aflatoxins analysis, they remain largely cumbersome, requiring extensive sample preparations, let alone very expensive equipment. This makes their routine use in analysis confined to laboratories. It is on the account of such limitations that it was necessary to develop more sensitive and better techniques for aflatoxins analyses [38]. Mainly used methods for analysis of aflatoxins in food and feed are the thin layer chromatography (TLC), liquid chromatography (LC), and immunochemical methods. TLC is one of the most widely used separation techniques in aflatoxin analysis. Since 1990, it has been considered the AOAC official method and the method of choice to identify and quantitate aflatoxins at levels as low as $1 \mathrm{ng} / \mathrm{g}$. Similar in many respects with TLC is LC. Usually TLC is used as a preliminary work for optimization of LC separation conditions [39].

\section{Chromatography}

Chromatography is one of the most popular methods to analyze mycotoxins such as Aflatoxins. Gas chromatography (GC), liquid chromatography (LC), High performance liquid chromatography (HPLC) and thin layer chromatography (TLC) are the most common techniques of chromatography. Out of these methods, LC and HPLC are the most used. In many cases, they are followed by fluorescence detections stage [40]. LC, TLC and HPLC are the most used quantitative methods in research and routine analysis of aflatoxins [41]. These techniques offer excellent sensitivities, but they frequently require skilled operators, extensive sample pretreatment and expensive equipment [42]. 
High performance liquid chromatography: High Performance Liquid Chromatography system of aflatoxin estimation has high precision, high sensitivity, and high automation. This method retains two phase systems: normal phase (liquid/solid, polar stationary phase) and reverse phase (liquid/ liquid, polar mobile phase) in conjunction with UV absorption and fluorescence detection. Reverse-phase HPLC is widely used for aflatoxin analysis [43]. HPLC is the most popular method for the analysis of mycotoxins in foods and feeds. Actually, it is a quantitative technique that is suited for online cleanup of sample extract and could be combined with different detectors [44].

The mycotoxins extracted from field samples undergo cleanup using commercial immune affinity columns before their analysis by HPLC. The columns are available for all the important mycotoxins: AFB1, AFB2, AFG1, AFG2, AFM2, ochratoxin A, T2 toxin, deoxynivalenol (vomitoxin), citrinin, fumonisins FB1, FB2, FB3, zearalenone, patulin and moniliformin. Multiplex columns are available for AFs, ochratoxin A and zearalenone. The rationale beyond the multiplex columns and for multiplex detection methods is the frequent production of more than one mycotoxin by a single fungus, and the frequent contamination of crops or silage with several species of fungi [45].

Thin layer chromatography: Thin layer chromatography (TLC), also known as flatbed chromatography or planar chromatography is one of the most widely used separation techniques in aflatoxin B1 analysis. Since 1990, it has been considered the AOAC official method. The TLC method is also used to verify findings by newer, more rapid techniques. The technique is widely used in laboratories throughout the world for food analysis and quality control. Applications of TLC have been reported in areas of food composition, intentional additives, adulterants, contaminants, etc. TLC has been used to analyze agricultural products and plants. It has advantages as, simplicity of operation; availability of many sensitive and selective reagents for detection and confirmation without interference of the mobile phase; ability to repeat detection and quantification; and cost effectiveness analysis, because many samples can be analyzed on a single plate with low solvent usage, and the time that TLC employs to analyze the sample is less that LC method [46]. Presumptive aflatoxin detection can be performed with thinlayer chromatography (TLC) as this method is a simple, robust technique, which is relatively is an inexpensive compared to high performance liquid chromatography methods [47].

\section{Enzyme Linked Immune Sorbent Assay Detection Method}

Aflatoxin detection has largely relied on competitive ELISA formats that are semi quantitative and depend on the use of conjugated toxin molecules. However, thelimitation of conventional immunoassay formats is largely due to the requirement that at least two epitopes of an antigen to be recognized and occupied. It is more challenging to develop a sandwich immunoassay assay for low molecular weight hapten molecules such as aflatoxins since the antibodies are much larger in size $(150 \mathrm{~K} \mathrm{Da})$ than the aflatoxin molecules $(\sim 0.312 \mathrm{~K} \mathrm{Da})$ themselves preventing combinatorial association of antibodies due to steric hindrance and limiting access of the antigen to secondary antibodies. It is also reported that the sandwich immunoassay for molecules of 1000 Daltons MW is less amenable for such applications.

\section{Economic and Health Impacts of Aflatoxin}

Aflatoxins have economic and health importance because of their ability to contaminate human food and animal feeds, in particular cereals, nuts and oilseeds. The toxins have adverse effects on plants, animals and humans. They are responsible for damaging up to $25 \%$ of the world's food crops, resulting in large economic losses in developed countries and human and animal disease in under-developed countries [48]. The toll of the effects on human health includes the cost of mortality, the cost of productive capacity lost when people die prematurely, the cost of morbidity, losses resulting from hospitalization and the cost of health care services, both public and private. There is intangible cost of pain, suffering, anxiety and reduction of the quality of life [49].

\section{Economic Impacts}

The magnitude of the economic impacts of the health consequences associated with consumption of aflatoxincontaminated food in developing countries is not known due to a lack of good data. According to them, the quantification of economic losses and estimation of the effects of aflatoxin on health will encourage Health Ministries to enforce standards and provide crucial advocacy to benefit the rural poor, such as improving their level of education about aflatoxin exposure [50]. The economic impact of aflatoxins derives directly from crop and livestock losses as well as indirectly from the cost of regulatory programs designed to reduce risks to animal and human health [51]. The chronic and acute exposures of cattle to aflatoxin cause significant economic loss. In addition to financial losses and economic damage to agricultural and animal husbandry, losses due to aflatoxin contamination of foods include major pharmaceutical and health costs to treat food poisoning. Consumption of aflatoxin contaminated feed reduces productivity of livestock [52].

Aflatoxin cause huge economic loss to Ethiopia and many developing countries. Commodities can be contaminated with aflatoxigenic fungi and aflatoxin at any time, before harvest and after harvest. The prevention of aflatoxin once occurs and treatment of aflatoxicosis is difficult. However, there are some mitigation mechanisms pre- and post-harvest. Moreover, awareness creation on aflatoxin contamination, its effect and management are essential.

\section{Public Health Significance}

Humans are exposed to aflatoxins by consuming foods contaminated with products of fungal growth. Evidence of acute aflatoxicosis in humans has been reported from many parts of the world, namely the Third World Countries. Conditions increasing the likelihood of acute aflatoxicosis in humans include limited availability of food, environmental conditions that favor fungal development in crops, and lack of regulatory systems for aflatoxin 
monitoring and control. The expression of aflatoxin related diseases in humans may be influenced by factors such as age, sex, nutritional status, and/or concurrent exposure to other causative agents such as viral hepatitis (HBV) or parasite infestation [53]. Over 5 billion people in developing countries worldwide are estimated to be at risk of chronic exposure to aflatoxins through contaminated foods. Aflatoxins are naturally occurring contaminants of food according to Guo [54].

Animals and humans are exposed to aflatoxins through consumption of contaminated products such as dairy products (e.g. milk, cheese, and yogurt) [55] Aflatoxin is both a food safety and public health issue because of its toxicity. When it is consumed, it can exert toxicity by altering intestinal integrity or modulate the expression of cytokines which can result to stunted growth in children and/or immune suppression. In the liver, aflatoxin may be transformed by certain $\mathrm{p} 450$ enzyme to its DNA reactive formAflatoxin-8-9-epoxide which binds to liver proteins and lead to their failure, resulting in acute aflatoxicosis or it may bind to DNA, contributing to aflatoxin induced hepatocellular carcinoma (liver cancer) [56].

\section{Control and Prevention of Aflatoxin}

Ultimately an early warning system should rely on multiple sources of information and triggers that would set in motion various responses for preventing or reducing an outbreak of aflatoxicosis. Triggers for action could also be based upon other factors which indicate or influence aflatoxin contamination, such as reporting of death among livestock or domestic animals which are often given lower quality grain. Modeling of aflatoxin contamination based on weather conditions from planting to post-harvest could also serve as a trigger [57]. To minimize risks associated with unavoidable exposure to AFs, regulation and monitoring measures must be supported by in field (preharvest) and storage (postharvest) interventions which may be applied to minimize AF contamination. AFM1 is excreted in milk of dairy animals following metabolism of AFB1 ingested with feed. Contamination of milk may, thus, be reduced either directly, decreasing AFM1 content of contaminated milk, or indirectly, decreasing AFB1 contamination in feed of dairy animals. Many methodologies developed to reduce AFM1contamination with both direct and indirect approaches have been extensively reviewed [58].

The presence and growth of Aspergillus on pre-harvested crops is dependent on the environment. Agricultural practices including proper irrigation and pest management can reduce aflatoxin contamination. Pre-harvest interventions include choosing crops with resistance to drought, disease, and pests and choosing strains of that crop which are genetically more resistant to the growth of the fungus and the production of aflatoxins. Feeds have to be kept hygienically and prevent molds formation by using available methods that is accessible for them in their environment Aware Extension workers and owners of livestock on impact of aflatoxin in feeds: implications to livestock and human health. Systemic vaccination of dairy cows and heifers has recently proved to be effective in reducing AFB1 carry-over as AFM1 in milk [59]. Reduction through food processing procedures: Sorting can remove a major part of aflatoxin contaminated units, but levels in contaminated commodities may also be reduced through food processing procedures that may involve processes such as washing, wet and dry milling, grain cleaning, dehulling, roasting, baking, frying, nixtamalization and extrusion cooking. These methods and their impact on aflatoxin reduction have been reviewed [60-72].

\section{Conclusion and Recommendations}

Generally, Aflatoxins are a group of mycotoxins produced by certain fungi, the occurrence of aflatoxins is influenced by certain environmental factors; hence the extent of contamination will vary with geographic location, agricultural and agronomic practices, and the susceptibility of commodities to fungal invasion during pre-harvest, storage, and or processing periods. Aflatoxins and the associated health disorders in humans and animals(which includes immune suppression, carcinogenic, teratogenic etc. ) have been recognized as a major health and economical problem which dictates measures to minimize the exposure by applying proper agricultural practice, storage of products and control of the products intended for human or animal consumption. The high toxicity and carcinogenicity of the aflatoxin contaminated compounds and their ability to cause various pathological conditions has led to widespread screening of foods and feeds potentially contaminated with them.

Therefore, based on the above conclusion the following recommendations are forwarded;

a. Feeds should be kept hygienically and stored dry condition to prevent molds formation

b. The farmers should select crops strains resistant to drought, disease, and pests

c. Awareness should be created on public about aflatoxicosis and its economic impact.

\section{Acknowledgements}

First of all, I would like to thank Allah, the Almighty, most merciful, the Self-sufficient master; whom all creature of the World by having full of things; that no one is out of his control and he open the right way for all to believe on him. Finally, I would like to extend my acknowledgements to my all family member especially for my father Fedlu Alewi for his moral and financial support.

\section{References}

1. Wang H, Zhou XJ, Liu YQ, Yang HM, Guo QL (2010) Determination of aflatoxin M1 in milk by triple quadrupole liquid chromatographytandem mass spectrometry. Food Additi and Cont-Part B 27: 1261-1265.

2. Felicia WU, Clare N, Marites T, Yan L (2011) The Health Economics of Aflatoxin: Global Burden of Disease, International Food Policy Research.

3. Ruiqian L, Qian Y, Thanaboripat D, Thansukon P (2004) Biocontrol of Aspergillus flavus and aflatoxin production. Sc Technol J 4: 1685-2044. 
4. Strosnider H, Azziz-Baumgartner E, Banziger M, Bhat RV, Breiman R (2006) Public Health Strategies for Reducing Aflatoxin Exposure in Developing Countries: A Workgroup Report. Environ Health Perspect 12: 1898-1903.

5. Bankole SA, Adebanjo A (2003) Mycotoxins in food in West Africa: Current situation and possibilities of controlling it. Afr J Biotechnol 2: 254-263.

6. Fernandez PV, Patriarca A, Locani O, Vaamonde G (2001) Natural Cooccurrence of aflatoxin and cyclopiazonic acid in peanuts grown in Argentina. Food Addit Contam 18: 1017-1020.

7. Kuilman MEM, Maas RFM, Fink-Gremmels J (2000) Cytochrome pp. 450

8. Chauhan NM, Washe AP, Minota T (2016) Fungal infection and aflatoxin.

9. Iqbal SZ, Asi MR, Selamat J (2014) Aflatoxin M1 in milk from urban andrural farmhouses in Punjab, Pakistan. Food Addit Contamin 7(1): 17-20.

10. Lewis L, Onsongo M, Njapau H, Schurz-Rogers H, Luber G, et al. (2005) The Kenya Aflatoxicosis Investigation Group, Aflatoxin contamination of commercial maize products during an outbreak of acute aflatoxicosisin Eastern and Central Kenya. Env Heal Persp 113: 1763- 1767.

11. Ayalew A, Fehrmann H, Lepschy J, Beck R, Abate D (2006) Natural occurrence of mycotoxins in staple cereals from Ethiopia. Mycopatho 162(1): 57-63.

12. Nisa A, Zahra N, Ejaz N, Hina S (2012) Detoxification of aflatoxinB1 in poultry and fish feed by various chemicals. Pakistan Journal of Scientific and Industrial Research 55(3): 154-158.

13. Wu F, Khlangwiset P (2010) Health economic impacts and cost-effectiveness of aflatoxin reduction strategies in Africa: Case studies in biocontrol and postharvest interventions. Food Additives and Contaminants 27: 496-509.

14. Cucci C, Mignani A, Dall"Asta C, Pela R, Dossena A (2007) A portable fluorometer for the rapid screening of M1 aflatoxin. Sensors and Actuators B: Chemical 126(2): 467-472.

15. Pattison M, McMullin P, Bradbury J, Alexander D (2008) Poultry Diseases ( $6^{\text {th }}$ edn). 38: 435-442.

16. Shephard GS (2008) Risk assessment of aflatoxins in food in Africa. Food Addit Sci 10: 62-115.

17. Ellis WO, Smith JP, Simpson BK (1991) Aflatoxins in food: occurrence, biosynthesis, effects on organisms, detection, and methods of control. Critc Rev Food Sci Nutr 30: 403-439.

18. Vander Felx-Klers HJ, Dekkers S, Kandhai MC, Jeurissen SMF, Booij CJH (2008) Indicators for early identification of re-emerging mycotoxin. Jour of Life Scien 57: 133-139.

19. Wild CP (2007) Aflatoxin exposure in developing countries: the critical interface of agriculture and health. Food Nutr Bull 28: 372-380.

20. Larsson P, Tjalve H (2000) Intranasal instillation of aflatoxin B1 in rats: Bioactivation in the nasal mucosa and neuronal transport to the olfactory bulb. Toxicol Sci 55(2): 383-391.

21. Massey TE, Stewart RK, Daniels JM, Liu L (1995) Biochemical and Molecular Aspects of Mammalian Susceptibility to Aflatoxin B1 Carcinogenicity. Proc Society Experiment Biol Medicine 208: 213-227.

22. Rawal S, Kim JE (2010) Coulombe R. Aflatoxin B1in poultry: Toxicology, metabolism and prevention. Res Vet Sci 89: 325-331.

23. Jarvis BB (2002) Chemistry and toxicology of molds isolated from water-damaged buildings, Mycotoxins and Food Safety. Adv Expt Med Bio 504: 43-52.

24. Moschini R, Sisterna M, Carmona M (2006) Modelling of wheat black point incidence based on meteorological variables in the southern $\mathrm{Ar}$ - gentinean Pampas region. Aus J Agric Res 57: 1151-1156.

25. Eaton DL, Ramsdel HS (1992) Species and diet related differences in aflatoxin biotransformation. In: Handbook of Applied Mycology. In: Bhatnagar D (Eds.), Marcel Dekker, New York, USA, 5: 157-182.

26. WHO (2000) Hazardous Chemicals in Humans and Environmental Health.

27. Cullen JM, Newberne PM (1994) Acute Hepatotoxicity of Aflatoxins. The Toxicology of Aflatoxins: Human Health, Veterinary, and Agricultural Significance, Academic Press p. 3-26.

28. Wang JS, Groopman JD (1999) DNA damage by mycotoxins.

29. Groopman JD, Cain LG, Kensler TW (1988) Aflatoxin exposure in human populations: Measurements and relationship to cancer. Crit Rev Toxicol 19: 113-145.

30. Williams JH, Phillips TD, Jolly PE, Stiles JK, Jolly CM, et al. (2004) Human aflatoxicosis in developing countries: a review of toxicolog $y$, exposure, potential health consequences, and interventions.

31. Méndez-Albores J, Villa G, Rio-García D, Martinez E (2004) Aflatoxin detoxification achieved with Mexican traditional nixtamalization process (MTNP) is reversible. J Sci Food and Agric 68: 1878-1881.

32. Bozoğlu FT, Tokuşoğlu Ö (2011) The Control Assessment and Possible Inactivation Mechanism on Mycotoxin Inactivation and Mycotoxic.

33. Gowda NKS, Swamy HVLN, Mahajan P (2013) Recent Advances for Control, Counteraction and Amelioration of Potential Aflatoxins in Animal Feeds. pp. 129-140.

34. Fazeli MR, Hajimohammadali M, Moshkani A, Samadi N, Jamalifar H, et al. (2009) Aflatoxin B1 binding capacity of autochthonous strains of lactic acid bacteria. J Food Prot 72(1): 189-192.

35. Velazhahan R, Vijayanandraj S, Vijayasamundeeswari A, Paranidharan V, Samiyappan R, et al. (2010) Detoxification of aflatoxins by seed extracts of the medicinal plant, Trachyspermumammi (L.) Sprague ex Turrill Structural analysis and biological toxicity of degradation product of aflatoxin G1. Food Cont 21(5): 719-725.

36. Yin Y, Yan L, Jiang J (2008) Biological control of aflatoxin contamination of crops. J Zhejiang Univ Sci B 9(10): 787-92.

37. Safard M, Zaini F, Hashemi SJ, Mehmoudi MAR, Khosravi AR, et al. (2010) Aflatoxin detoxification in rice using citric acid. Iranian J Publ Health 39(2) :24-29.

38. Alex PW, Deborah W, Peter CV, Joseph F (2014) Hawumba Methods for Detection of Aflatoxins in Agricultural Food Crops. J Appl Chem 1: 3-14.

39. Cigić KI, Prosen H (2009) An Overview of Conventional and Emerging Analytical Methods for the Determination of Mycotoxins. Int J Mol Clini Nutr 80: 1106-1122.

40. Cavaliere C, Foglia P, Pastorini E, Samperi R, Lagana A (2006) Liquid chromatography/tandem mass spectrometric confirmatory method for dete rminigaflatoxin M1 in cow milk: Comparison between electrospray and atmospheric pressure photoionization sources. J Chrom A 1101(12): 69-78.

41. Vosough M, Bayat M, Salemi A (2010) Matrix-free analysis of aflatoxins in pistachio nuts using parallel factor modeling of liquid chromatography diodearray detection data. Analytica chimica acta 663(1): 11-18.

42. Sapsford K, Ngundi M, Moore M, Lassman M, Shriver-Lake L, et al. (2006) Rapid detection of food-borne contaminants using an array biosensor. Sensors and Actuators B: Chem 113(2): 599-607.

43. Mehan VK (1997) Analytical and immuno-chemical methods for the analysis of aflatoxins in groundnuts and groundnut products. In: Mehan VK, Gowda CLL (Eds.), Aflatoxin contamination problems in groundnut in Asia. Proceedings of the First Asia Working Group Meeting. Patancheru, India: International Crops Research Institute for the Semi- Arid Tropics p. 49-65. 
44. Li J, Yu Y, Tian M, Wang H, Wei F, et al. (2006) Simultaneous determination of aflatoxins, zearalenone and ochratoxin A in cereal grains by immune affinity column and high-performance liquid chromatography coupled with post-column photo chemical derivatization. 24(6): 581584.

45. Gonza'lez pereyra S, Das M, Khanna S (2008) Quantitative determination of aflatoxin B1- oxime by column liquid chromatography with ultraviolet detection. Jour of Chromato 933: 91-97.

46. Sherma J (2000) Thin-layer chromatography in food and agricultural analysis. J Chrom A 880(1-2): 129-147.

47. Gilbert J, Anklam E (2002) Validation of analytical methods for determining mycotoxins in foodstuffs. Trac-Trends in Analyti Chem 21(6-7): 468-486.

48. Abbas HK, Weaver MA, Zablotowicz RM, Horn WT, Shier WT (2005) Relationships between aflatoxin production and Sclerotia formation among isolates of Aspergillus section Flavi from the Mississippi Delta. Eur J Plant Pathol 112: 283-287.

49. Bhat RV, Basanthi S (2003) Food safety in Food Security and Food Trade: Mycotoxin food safety risks in developing countries. 2020 vision for food, agriculture and environment. Focus 10 Brief 3. International Food Policy Research Institute, Washington, USA. Bioactives. In Fruits and Cereals pp. 625.

50. Wu F, Narod C, Tiongco M, Liu Y (2011) The health economics of aflatoxin: the global burden of disease.

51. Bennett JW, Klich M (2003) Mycotoxins. Clinical toxicology Micro Rev pp. 497516.

52. Dawit G, Szonyi B, Tegegne A, Hanson J, Grace D (2016) Aflatoxin contamination of milk and dairy feeds in the Greater Addis Ababa milk shed, Ethiopia. Food Control 59: 773-779.

53. Duarte-Vogel S, Villamil-Jiménez LC (2006) Mycotoxins in public health. Rev Salud Publi 1: 129-35.

54. Guo B, Widstrom N (2000) Control of preharvest aflatoxin contamination in corn: Fungus plant insects' interactions and control strategies. Recent Research Developments in Agricultural and Food Chemistry 4: 165-176.

55. Prandini A, Tansini G, Sigolo S, Filippi L, Laporta M, et al. (2009) On the occurrence of aflatoxin M1 in milkand dairy products. Food Chem Toxic 47(5): 984-991.

56. Alloysius Chibuike O, Ositadinma Chinyere (2016) Public Health.

57. De la Campa R, Hooker DC (2005) Modeling effects of environment, insect.

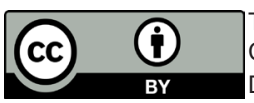

This work is licensed under Creative

Commons Attribution 4.0 License

DOI: 10.19080/JDVS.2019.12.555837
58. Jard G, Liboz T, Mathieu F, Guyonvarc'h A (2011) Lebrihi, A. Review of mycotoxin reduction in food and feed: From prevention in the field to detoxification by adsorption or transformation. Food Addit Contam Part A 28: 1590-1609.

59. Giovati L, Gallo A, Masoero F, Cerioli C, Ciociola T, et al. (2014) Vaccination of heifers with an aflatoxin improves the reduction of aflatoxin B1 carry over in milk of lactating dairy cows. 9(4): e94440.

60. Fandohan P, Hell K, Marasas WF (2008) Food processing to reduce mycotoxins in Africa. In Leslie Mycotoxins: Detection methods, managem ent, public health and agricultural trade. CABI Publishing, Wallingford, UK, pp. 302-309.

61. Brown RL, Chen ZY (2001) Resistance to aflatoxin accumulation in kernels of maize in breeds selected for ear rot resistance in West and Central Africa. J Food Prot 64(3): 396-400.

62. Contam Part a Chem Anal Control Expo Risk Assess Food Additives \& Contaminants: Part A: 25(10): 1246-1256. contamination in maize collected from Gedeo zone, Ethiopia.

63. Corrier DE (1991) Mycotoxicosis: Mechanisms of immune suppression.

64. Damage, and Bt genotypes on fumonisin accumulation in maize in $\mathrm{Ar}-$ gentina and the Philippines." Mycopato., 159(4): 539-52.

65. Gashaw M (2015) Review on Mycotoxins in Feeds: Implications to Livestock and human health E3 Journal of Agricultural Research and Development 5(3): 0137-0144.

66. Hsu IC, Metcalf RA, Sun T, Welsh JA, Wang NJ, et al. (1991) Mutational hotspot in the p53 gene in human hepatocellular carcinomas. Nature 350: $427-428$.

67. International Institute 2033 K Street, NW Washington, DC 20006-1002 USA. Immunol. Immunopathol 30:73-87.

68. Mediated metabolism and cytotoxicity of aflatoxin B1 in bovine hepatocytes. Toxicol In Vitro 14: 321-327.

69. Nyamongo J, Backer L, Dahiye AM, Misore A, Decoct K, et al. (2005) The Kenya Aflatoxicosis Investigation Group. Aflatoxin contamination of commercial maize products during an outbreak of acute aflatoxicosis in Eastern and Central Kenya. Environ Health Perspect 113: 1763-1767.

70. Shivender SS, Anupreet K (2012) Aflatoxin B1: Toxicity, characteristics and analysis: Mini review Global Ad. Res J Chem Mat Sci 1(4): 63- 70

71. Significance of Aflatoxin in Food Industry (2016) A Rev Euro J Clini Bio Sci 2(5): 51-58.

72. Wolde M (2012) Effects of aflatoxin contamination of grains in Ethiopia. J Agri Sci 7(4): 1298-1308.

\section{Your next submission with Juniper Publishers will reach you the below assets}

- Quality Editorial service

- Swift Peer Review

- Reprints availability

- E-prints Service

- Manuscript Podcast for convenient understanding

- Global attainment for your research

- Manuscript accessibility in different formats

( Pdf, E-pub, Full Text, Audio)

- Unceasing customer service

Track the below URL for one-step submission https://juniperpublishers.com/online-submission.php 